\title{
IMPRENSA OPERÁRIA: COMUNICAÇÃO E ORGANIZAÇÃO
}

Jorge Luiz Jardim ${ }^{1}$

O final do século XIX representou para o Rio Grande do Sul um período de grandes transformações em vários setores, tanto na sua economia como no seu sistema de organização política e social ${ }^{2}$. O processo abolicionista, as idéias republicanas e a imigração mudaram a fisionomia da sociedade rio-grandense. Entre 1872 e 1890 a sua população dobrou $^{3}$, as cidades cresceram e tem início um significativo surto industrial, quando comparado ao resto do país. As primeiras indústrias irão se localizar nos principais centros urbanos como Rio Grande, Pelotas e Porto Alegre, secundariamente nos núcleos coloniais como Caxias e São Leopoldo. Da última década do século passado até os anos 20 deste século temos uma mudança gradativa no perfil agrário e pastoril do estado para um "outro Rio Grande"4 - urbano e industrial.

Dentre os muitos aspectos que sofreram transformações encontra-se o das comunicações. Urbanização e industrialização inegavel-

1 Mestre em História do Brasil pela PUCRS, Professor e Pró-Diretor Administrativo do Centro de Ciências da Comunicação da UNISINOS.

2 LOVE, Joseph L. O regionalismo gaúcho. São Paulo, Perspectiva: 1975, p. 17 27.

3 Idem, p.19.

4 PESAVENTO, Sandra Jatahy. "Introdução". In: FAGUNDES, Lígia Ketzer \& outros. Memória da indústria gaúcha (1889-1930). Porto Alegre: UFRGS/FEE, 1987 , p. 8. 
mente são fatores dinamizadores e transformadores dos meios de comunicação. Numa época em que os grandes meios de comunicação atuais não existiam, a palavra impressa ${ }^{5}$ era o meio mais ágil de circulação da informação e das idéias; de modo especial o jornalismo. E nesta época falar em jornalismo é o mesmo que dizer jornal ${ }^{6}$. Se nesta conjuntura a fundação do Correio do Povo em 1895 é considerado um marco divisório na história do jornalismo gaúcho ${ }^{7}$, certamente se está esquecendo das primeiras manifestaçōes da imprensa ${ }^{8}$ operária, anteriores a esta data.

A palavra impressa e o jornalismo se desenvolveram paralelamente ao capitalismo e à industrialização. A impressão por si só já pode ser considerada uma forma de indústria, pois substitui o trabalho artesanal por um processo mecânico. O seu desenvolvimento ao longo dos últimos cinco séculos foi de capital importância, como afirma Peterson:

"A palavra impressa foi tâo importante que é de se duvidar que a nação-estado moderna tivesse podido surgir sem ela. Durante séculos foi, em larga escala, através do material impresso de uma forma ou de outra que os ideais, aspirações, tradiçōes comuns e alianças políticas foram mantidas em amplas áreas. Os impressos cumpriram sozinhos as funções que hoje esperam venham a ser compartilhados por todos os outros meios de comunicação. Os veículos impressos de comunicação informavam e esclareciam o público, interpretavam os eventos e as questōes, desafiavam a autoridade caprichosa, divertiam a população, e mesmo, até certo ponto, conseguiam reunir os compradores e vendedores de bens e serviços."

5 Palavra impressa compreendendo toda a forma de impressos: livros, revistas, jornais, folhetos, panfletos etc.

6 "No passado o termo jornalismo era adequado para descrever os meios de comunicação. (...). A palavra jornalismo servia, então, para descrever os meios de comunicaçāo nos dias em que a maior parte das comunicaçōes eram efetuadas pelas revistas e jornais". PETERSON, Theodore \& outros. Os meios de comunicação e a sociedade moderna. Rio de Janeiro: Ediçōes G R D, 1966, p. 16.

7 Ver ERICKSEN, Nestor. O sesquicentenário da imprensa rio-grandense. Porto Alegre: Sulina, 1977, p. 33 e 47.

8 O termo imprensa será empregado no sentido de publicação periódica, jornal ou revista, tendo o mesmo sentido de jornalismo.

PETERSON, ob. cit., p. 17. 
No Rio Grande do Sul desde 1827, com o surgimento do Diário de Porto Alegre, havia proliferado um grande número de jornais, privilegiando-se sobremaneira esta forma de comunicação. Fato este tão significativo que levou alguns autores a considerar que a história da imprensa gaúcha se confundia com a própria história da evolução política e social do Rio Grande do Sul ${ }^{10}$. Este fato se confirma pela análise da imprensa política desde a Revolução Farroupilha, passando pelo debate entre conservadores e liberais, com seus órgãos O Conservador e A Reforma, respectivamente; pela expressão das idéias republicanas através de A Federação a partir de 1884; se confirma também pelo nascimento de uma imprensa socialista e libertária que pugnará pela defesa do trabalhador urbano e assalariado, de modo especial o trabalhador fabril. Ela surge em 1892 nas cidades de Pelotas e Porto Alegre com aqueles que se poderia denominar de os primeiros jornais de cunho operário e contestador do sistema capitalista ora em expansão no Rio Grande do Sul. Eram eles O Operário, em Pelotas, e L'Avvenire, em Porto Alegre. Este fenômeno também expressava a transformação política e social do estado, que ao desenvolver sua indústria e as relações capitalistas criava novas classes sociais que buscavam a sua expressão.

Se por um lado o Correio do Povo vem revolucionar o jornalismo e retirá-lo das peias do partidarismo, vendendo a idéia da isenção, da independência e da posição acima dos partidos ${ }^{11}$, no entanto não supera a posição de classe de outros órgãos de imprensa. Ele expressa na verdade uma nova fase do capitalismo nos meios de comunicação: o jornal empresa ${ }^{12}$. Mas o mesmo fenômeno traz consigo a emergência de uma classe operária urbana que busca espaço político e direitos sociais. $\mathrm{E}$ isto não pode ser feito, enquanto empreendimento coletivo, sem o emprego de algum meio de comunicação que una os interesses comuns e difunda idéias de organização. É neste momento que os trabalhadores começam a sua organização e tem início o que se convencionou chamar de "movimento operário".

10 SILVA, Jandira M. M. da \& outros. Breve história da imprensa sulriograndense. Porto Alegre: CORAG, 1986, p. 124.

11 ERIKSEN, ob.cit, p. 47.

12 Ver SODRÉ Nelson Werneck. História da imprensa no Brasil. Rio de Janeiro: Civilização B́rasileira, 1966, p. 315. 
O surgimento da imprensa operária já corresponde a um certo nível de desenvolvimento do movimento operário, pois a publicaçāo de um jornal, mesmo que pequeno, requer pelo menos que algumas pessoas tenham adquirido consciência política em relação ao grupo social que defendem. Precisam de recursos materiais e técnicos e, acima de tudo, um público receptor que possa acolher e apoiar a publicação,

“... a imprensa operária, daí por diante, desempenhará a sua função de mobilizadora e organizadora de massas e de orientadora e impulsionadora do movimento operário."13

Os autores que estudaram o movimento operário no Brasil, na sua unanimidade, salientam a importância do jornal como mobilizador e organizador dos trabalhadores durante a República Velha. Em cada organização operária que se fundava, uma das primeiras providências era a publicação de um jornal, além disso grupos isolados, embora não ligados a uma categoria profissional específica, mas que se propunham a falar em nome dos trabalhadores, também publicavam os seus periódicos. Estes jornais começam a aparecer de forma esparsa antes da proclamação da República ${ }^{14}$, geralmente de tendência socialista, mas na última década do século passado surgem também os de tendência libertária, que vão, de forma gradativa, se tornar dominantes, formando estes jornais espalhados por várias cidades do Brasil uma ampla rede de comunicação visando a orientação e organização dos trabalhadores.

Ângela de Castro Gomes, ao estudar as correntes anarquistas no Rio de Janeiro na Primeira República, constatou um grande número de publicações periódicas ali editadas por seus militantes ${ }^{15}$, lembrando que isso não se constituía em apenas um fenômeno local, mas da própria característica da militância anarquista, pois

13 GARCIA, Evaldo da Silva. "A imprensa operária e socialista brasileira do século XIX”. Estudos Sociais, n. 19, fevereiro de 1964, p. 263.

14 Ver artigo citado de GARCIA; FERREIRA, Maria Nazareth A imprensa operária no Brasil 1880-1920. Petrópolis: Vozes, 1978; p. 91-102; HARDMAN, Francisco Foot \& LEONARDI, Victor. História da indústria e do trabalho no Brasil: das origens aos anos vinte. São Paulo: Global, 1982. p. 120-127; BANDEIRA, Moniz \& outros. $O$ ano vermelho: a revolução russa e seus reflexos no Brasil. São Paulo: Brasiliense, 1980, p. 14-18.

15 GOMES, Angela de Castro. A invenção do trabalhismo. São Paulo/Rio de Janeiro: Vértice/IUPERJ, 1988, p. 93. 
"O pequeno jornal não diário foi, desde Proudhon, na década de 1850 , a forma típica de atuação dos militantes anarquistas." 16

É claro que isto se aplica também a outras correntes de pensamento organizadoras dos trabalhadores, como é o caso dos socialistas, pois em todas as sociedades a estrutura das comunicações é de fundamental importância para a expressão política e a difusão de idéias. E nenhum líder pode prescindir de um veículo de comunicação para divulgar as suas idéias ${ }^{17}$. O jornal se constituía num meio dinâmico e eficaz de propagação de idéias entre os trabalhadores. Por certo havia outras formas de comunicação, como o livro, o panfleto, o folheto e a palavra oral. O livro pelo seu custo e dificuldades de circulação tinha suas limitações de penetração no meio operário ${ }^{18}$; o panfleto certamente foi um bom meio de comunicação — ágil, de baixo custo e fácil distribuição _ porém não tinha o status do jornal devido a sua eventualidade e especificidade na abordagem de determinada questão ${ }^{19}$. Já o folheto foi bastante usado no Rio Grande do Sul, de modo especial pelos libertários ${ }^{20}$. A palavra oral também se constituiu num extraordinário instrumento de comunicação e propagador de idéias. Basta ver os inúmeros convites ou notícias de conferências promovidas pelas organizações operárias que aparecem nas páginas dos jornais, algumas delas são inclusive transcritas nos jornais operários.

Maria Nazareth Ferreira com o seu trabalho pioneiro sobre a imprensa operária também salienta a importância do jornal:

16 Ibid., p. 134.

17 PYE, Lucian W. Comunicações e desenvolvimento político. Rio de Janeiro: Zahar, 1967, p. 52.

18 Mas não se pode negar a sua importância. Quase todos os jornais operários estampavam anúncios de livros dos grandes teóricos do movimento operário. Geralmente a redação servia como intermediária na aquisição destas obras, muitas delas do exterior. Embora se saiba que boa parte dos trabalhadores era analfabeta, não quer dizer que estavam impossibilitados de ter acesso ao conteúdo dos livros, pois os letrados e os líderes que faziam a sua leitura transmitiam seus ensinamentos por intermédio de conferências públicas e nas reuniōes operárias.

Os jornais operários noticiam freqüentes distribuiçōes de panfletos, especialmente diante de acontecimentos importantes, como greves, $1^{2}$ de Maio etc.

O primeiro de que tive notícia foi "As bases do sindicalismo" de Emílio Pouget. Inicialmente publicado em $1906 \mathrm{em}$ forma de folhetim em A Luta de Porto Alegre, depois em forma de folheto pelo "Grupo Editor de Propaganda". Cf. A Luta, 3 de fevereiro de 1907, p. 2. 
"A utilização do jornal como veículo de comunicação foi de grande proveito para a organização da classe trabalhadora brasileira. Basta averiguar a intensa rede de jornais que surgiu com a fundação de ligas e uniões e a grande tiragem que estes jornais atingiram nos períodos que antecederam os movimentos grevistas. Em todos os acontecimentos relevantes que empolgavam os trabalhadores brasileiros o jornal mostrou-se o principal veículo de comunicação. Através de suas páginas a liderança operária orientava as massas trabalhadoras. As palavras dos líderes eram imprescindíveis ao encaminhamento das questôes operárias." 21

Esta intensa rede de jornais a que a autora se refere, também está presente no Rio Grande do Sul no período da República Velha. No seu trabalho, Maria Nazareth Ferreira coloca o estado do Rio Grande do Sul em terceiro lugar em número de títulos publicados até 1920, com uma percentagem de 5 por cento do total de títulos levantados no Brasil $^{22}$. Evidentemente que esta sua pesquisa já está superada pelo levantamento de outros dados. Em trabalho posterior ${ }^{23}$ a autora amplia um pouco a sua lista de jornais, inclusive acrescentando novos títulos publicados no Rio Grande do Sul. Com base na presente pesquisa e nas de Sílvia Regina Ferraz Petersen e de João Batista Marçal24 ${ }^{24}$ podemos dizer que o número de títulos de jornais operários editados no estado é significativamente maior do que o citado por Ferreira. Até 1930 é bem possível que uma quantificação mais precisa manteria o Rio Grande do Sul no terceiro lugar, depois de São Paulo e do Rio de Janeiro, mas a sua participação na percentagem sobre o total certamente se elevaria. Indicava esta rede de jornais, que se espalharam por diversas cidades do Rio Grande do Sul, a presença e a voz dos trabalhadores, suas denúncias contra o regime de opressão a que estavam submetidos, os seus anseios e sonhos de uma sociedade reno-

\footnotetext{
21 FERREIRA, ob. cit., p. 15.

22 Ibid., p. 89.

23 FERREIRA, Maria Nazareth. A imprensa operária no Brasil. São Paulo: Ática, 1988.

24 PETERSEN, Silvia Regina Ferraz Guia para o estudo da imprensa dos trabalhadores do Rio Grande do Sul (1874-1940). Porto Alegre: Ed. da Universidade, UFRGS/FAPERGS, 1989; MARÇAL, João Batista. Um século de imprensa operária no Rio Grande do Sul (1874-1974). (Trabalho inédito do qual tivemos acesso a algumas partes).
} 
vada e mais justa, onde os trabalhadores tivessem mais direitos e reconhecimento:

\begin{abstract}
"Na difusão destas idéias, a imprensa operária representou talvez o papel mais importante, pois ainda que os jornais tivessem duração efêmera e uma tiragem reduzida, constituíam o veículo de penetração mais sistemática junto aos operários e neles escreviam os elementos mais politizados das associações operárias." 25
\end{abstract}

Se os historiadores de hoje atribuem todos estes valores e importância à imprensa operária, o movimento operário e os jornais não deixavam por menos. Uma das propostas apreciadas no primeiro congresso de trabalhadores realizado no Brasil foi a criação de um jornal socialista $^{26}$. Este evento ocorreu justamente no Rio Grande do Sul, na cidade de Porto Alegre, nos dias 1 e 2 de janeiro de 1898 e se denominou "I Congresso Operário do Rio Grande do Sul". ${ }^{27}$ Embora este jornal socialista não tenha sido criado, permaneceu a idéia da importância do jornalismo para a organização dos trabalhadores. Supõe-se, na falta de maiores dados, que este periódico seria o órgão da Confederação Operária Sul-rio-grandense, criada no Congresso ${ }^{28}$, que na verdade não passou de uma comissão organizadora, a qual, pela sua inoperância em publicar os resultados do Congresso, foi duramente criticada pelo Echo Operário de Rio Grande ${ }^{29}$. Por esta época já se publicava no estado, há quase dois anos, este órgão socialista dirigido por Antônio Guedes Coutinho junto com O Social, de Alegrete, sob a direção de Eduardo Mallmann. Ambos haviam estado em Porto Alegre participando do Congresso e ratificaram suas resoluçóes, embora Guedes Coutinho, junto com a delegação de Pelotas, tenha chegado atrasado, pois seu navio encalhou na vinda à capital. ${ }^{30}$

No I Congresso Operário Brasileiro realizado em 1906 no Rio de Janeiro discute-se a necessidade de propagar os meios de "emancipação do proletariado" e de defender as reivindicações eco-

25 PETERSEN, Sílvia Regina Ferraz. "A mulher na imprensa operária gaúcha do século XIX”. Revista de História, UFRGS, v.1, 1986/1987, p. 84.

26 RODRIGUES, Edgar. Socialismo e sindicalismo no Brasil 1675-1913. Rio de Janeiro: Laemmert, 1969 p. 74.

27 ECHO OPERÁRIO, Rio Grande, 1 de fevereiro de 1898 , p. 1.

28 Idem, 27 de fevereiro de 1898 , p. 3.

29 Idem, 7 de agosto de 1898, p. 1.

30 Idem, 18 de janeiro de 1898 , p. 1. 
nômicas dos trabalhadores, para tanto aconselha o uso do jornal como meio de propaganda. ${ }^{31} \mathrm{O}$ Congresso delibera pela criação do jornal $\mathbf{A}$ Voz do Trabalhador, que só inicia sua circulação em 1908. Da mesma forma, o II Congresso realizado em 1913 no Rio de Janeiro considera que a imprensa é o meio mais eficiente de orientar as massas populares.. ${ }^{32}$ Salienta que os capitalistas defendem os seus interesses diante da opinião pública por intermédio da "imprensa comercial", portanto caberia aos trabalhadores disseminar por toda a parte a imprensa operária, sua opositora,

"que venha realizar o saneamento social, intelectual e moral do povo, segundo os mais racionais e elevados ideais de regeneração, que formem nos trabalhadores verdadeira consciência e sólidas convicçōes, para que em todo o tempo e lugar estejam aptos para se colocarem à altura de todas as eventualidades." 33

Com base em todo este idealismo o Congresso aconselha que todos os sindicatos, entidades operárias e trabalhadores em geral criem jornais nos mais diversos lugares e que auxiliem os já existentes.

A importância atribuída aos jornais pelo movimento operário está expressa inclusive em muitos estatutos de organizaçóes e de sindicatos operários. É o caso dos estatutos da Sociedade União Operária de Rio Grande, fundada em 1893, sendo uma das mais estáveis entidades de trabalhadores do estado, permanecendo ativa até pelo menos a década de 60 . No capítulo referente aos fins da sociedade constava no artigo $2^{\circ}$ :

"Parágrafo 16 - Fundar um jornal para a defesa dos interesses sociais e do operariado em geral.

Parágrafo 17 - Sempre que possível será grátis a distribuição deste jornal aos associados." 34

31 Ver as resoluçōes do Congresso em PINHEIRO, Paulo Sérgio \& HALL, Michael M. A classe operária no Brasil (1889-1930) - documentos. São Paulo: Alfa Omega, 1979, v. 1, p. 42-3.

32 Ibid., p. 196-7.

33 "Relatório da Confederação Operária Brasileira contendo as resoluçōes do segundo congresso operário brasileiro reunido no Rio de Janeiro nos dias 8, 9, 10, 11, 12 e 13 de setembro de 1913 ”. In: Ibid., p. 197.

34 ESTATUTOS DA UNIÃO OPERÁRIA. Rio Grande: Tipografia do Diário de Rio Grande, 1903. 
Também nos estatutos da Federação Operária de Pelotas constava na letra " $\mathrm{f}$ " do artigo 1 ":

"Pugnar pela fundação de bibliotecas e escolas; publicar manifestos, folhetos e um jornal, e levar a efeito conferências e comícios, com o fim de desenvolver a propaganda pelos direitos do proletariado, instruindo e educando." 35

O Sindicato dos Condutores de Veículos à Tração Animal de Rio Grande tinha no artigo $1^{\mathrm{O}}$ do seu estatuto:

"Publicar um jornal defensor da classe ou auxiliar outro que exista no mesmo local, cujo programa seja a defesa dos interesses proletários." 36

Em 1911 a Federação Operária do Rio Grande do Sul - FORGS aprovava seus estatutos na sessão da Comissão Central realizada em 15 de agosto presidida por Lucídio Marinho Prestes e secretariada por Polydoro Santos, neles constava na letra " $\mathrm{f}$ " do artigo 1 :

"Manter escolas, publicar manifestos, folhetos e jornais, promover conferências com o fim de desenvolver a propaganda pelos direitos do proletariado." ${ }^{37}$

Já no ano seguinte, sob a orientação dos anarco-sindicalistas, a FORGS publicará A Voz do Trabalhador, e até a década de $30 \mathrm{em}$ períodos intermitentes terá como porta-vozes e orientadores do movimento operário do Rio Grande do Sul outros jornais, apostando sempre seus diversos dirigentes nesta forma de comunicação com a massa de trabalhadores que deveria orientar. Editará entre 1919 e 1928 O Syndicalista, que seguramente está entre os principais jornais operários brasileiros anteriores a 1930. Entre 1933 e 1935 publicará A Voz do Trabalhador, sob a orientação dos comunistas.

Os partidos operários fundados no Rio Grande do Sul pelos socialistas também darão fundamental importância à publicação de jornais como forma de propaganda de seus programas. No estatuto do

35 A VOZ DO TRABALHADOR, Rio de Janeiro, 5 de março de 1915, p.3.

36 ESTATUTOS DO SINDICATO DOS CONDUTORES DE VEÍCULOS À TRAÇÄO ANIMAL - FUNDADO EM 15 DE OUTUBRO DE 1911, Rio Grande do Sul, s/ed., s/d.

37 ESTATUTOS DA FEDERAÇĀO OPERÁRIA DO RIO GRANDE DO SUL. Manuscrito. Cópia registrada no Cartório de Registros Especiais de Porto Alegre. 
Partido Socialista fundado em $1^{\varrho}$ de maio de 1898 em Rio Grande constava o seguinte artigo:

"O partido terá um órgão na imprensa que advogue os seus direitos e faça a propaganda, sendo a sua redação entregue a uma comissāo eleita pela assembléia." ${ }^{\text {38 }}$

Este órgão era o Echo Operário que a partir da fundação do partido passa a ser o seu porta-voz. Da mesma forma em 1905, quando um grupo de socialistas de Porto Alegre liderado por Francisco Xavier da Costa funda o Partido Operário Rio-Grandense, com ele nasce A Democracia, para divulgação das idéias pregadas pelo partido.

As páginas e os editoriais destes jornais estavam cheios de apelos dirigidos aos trabalhadores para que mantivessem e desenvolvessem estes órgãos defensores de seus interesses. Isto era feito quase sempre na forma de apologia à imprensa com o objetivo de demonstrar a sua importância para as lutas dos trabalhadores. Estes apelos partem de "minorias com linguagem articulada", como denominou E.P. Thompson ${ }^{39}$, que são os militantes mais ativos do movimento operário, seus líderes e os que escrevem e editam os jornais. Falam para e em nome da grande massa de trabalhadores, que pela sua baixa politização nem sempre atende a estes chamamentos, por isso é preciso reforçá-los constantemente. Em outubro de 1897, tendo publicado já 60 números nos seus 15 meses de existência, o Echo Operário enfrentava sérias dificuldades financeiras. Sua manutenção dependia tão somente de 200 assinaturas a mil réis cada uma. ${ }^{40} \mathrm{Em}$ contundente artigo assinado por Gonçalo Calvo ${ }^{41}$ irá apelar ao operariado em favor do jornal, demonstrando a importância da imprensa operária. Para reforçar sua idéia busca a comparação com a Europa:

"Não é preciso pôr em relevo o valor que a imprensa dá a uma classe para o seu progresso moral e material, pois que isto é bastante conhecido dos próprios operários e artistas. Na culta Europa, eles sabem muito bem o quanto a sua imprensa tem concorrido para benefício das classes proletárias; e aí está a razão por-

38 ECHO OPERÁRIO, Rio Grande, 22 de janeiro de 1899, p.3.

39 THOMPSON, E.P. A formação da classe operária inglesa. Rio de Janeiro: Paz e Terra, 1987, v.1, p. 57.

40 ECHO OPERÁRIO, Rio Grande, 24 de outubro de 1897 , p. 3.

41 Pseudônimo de Augusto de Souza Freitas. 
que lá existem jornais diários, de primeira ordem e que pesam sensivelmente no conceito público e dos governos." 42

No ano seguinte, em Porto Alegre, Francisco Xavier da Costa, que será um dos principais redatores de jornais operários, escreve na Gazetinha defendendo a necessidade da expansão da imprensa operária por todo o estado, mostrando a sua importância como instrumento de ação na luta dos trabalhadores por melhores condições de vida na sociedade:

"No estado já uma folha existe, órgão das classes laboriosas: é o Echo Operário, do Rio Grande, projeta-se a fundação de outro em Alegrete, graças aos aplausíveis esforços do valente propagandista Eduardo Mallmann; porém é pouco ainda, porque nós, lutadores constantes do Progresso, esquecidos demais, se quisermos, de fato, conquistar a plena independência indispensável ao nosso bem-estar - que deve ser relativo ao esforço que empregamos no mourejar do labor cotidiano - precisamos agir em uma esfera de ação mais vasta, mais franca e pública, mais produtiva talvez, do que as das tribunas de nossas associaçōes; precisamos erguer na imprensa o nosso eco, aqui na capital como no Rio Grande e fazer o mesmo em Pelotas, Bagé, em Alegrete, em todas as cidades, enfim em todas as vilas, em todos os povoados por menor que seja e sua população."43

Naturalmente, Xavier da Costa, como militante e líder operário que já por esta época se destacava entre o operariado porto-alegrense como organizador da classe, compreende que não bastava sua ação pessoal e a da palavra oral para a difusão das idéias de organização dos trabalhadores. Era preciso levar a doutrinação escrita onde "não se pode por enquanto levar a doutrinação verbal", como referia na seqüência do artigo citado. Isto tanto para despertar nos trabalhadores o espírito de luta para vencer a opressão, como para fazê-los compreender que o remédio para os males econômicos e sociais que os atingiam estava nas suas próprias mãos e "mais ainda, que esse remédio vai sendo usado, com êxito, por outros co-irmãos”. Esta consciência do valor estratégico do jornal para o movimento operário, quer como manifestação orgânica do próprio movimento, ou como palavra de grupos engajadas na defesa das bandeiras de luta dos trabalhadores, foi

42 ECHO OPERÁRIO, Rio Grande, 24 de outubro de 1897, p. 3-4.

43 A GAZETINHA, Porto Alegre, 2 de julho de 1898, p. 2. 
constantemente propagandeada e reforçada em diferentes momentos e órgãos operários.

Em 1912 A Voz do Trabalhador publica artigo de Plácido Peres de Bittencourt enviado de Bagé que diz:

"Ninguém poderá contestar que a maior necessidade do movimento operário que ora se agita, é a criação de um jornal, órgão de propaganda operária.

Nada poderá produzir resultados práticos em favor da idéia que defendemos, como o jornal.

Com o poder da imprensa já quebraram-se as algemas, fontes do obscurantismo, da escravidão.

(...).

O jornal é a boa e pacífica arma de defesa; entra em todas as casas, dissemina todas as idéias, invade todos os centros e pugna por todas as liberdades." ${ }^{\prime 4}$

Despertar uma maioria silenciosa, fazê-la reagir frente à opressão que sofre, objetivos buscados pelos militantes, não podem prescindir de um meio de comunicação, nisto o jornal se torna uma forma de ação.

"A necessidade inelutável de alento, de estímulo ao espírito de combatividade no nosso meio, leva-nos, quase força-nos a confiar nos benefícios de um transmitidor de impressões e de idéias, que seja o jornal ... (...) Mas... realmente, que é que sentimos, nós operários, neste momento, que nos leva à publicação de um jornal? Creio que é fácil a resposta: a necessidade de reagir contra o meio que nos envolve numa quase asfixiante atmosfera. Para reagir porém, contra um peso tâo superior a uma simples força individual, é necessário um aumento considerável de forças individuais, até formarmos uma força coletiva." 45

Esta força coletiva é composta e buscada com um sentido, aquele de se opor ao capital e à sua dominação. Nesta luta é a imprensa sustentada e dirigida pelos trabalhadores que pode obter bons resultados, apesar de todas as dificuldades e desânimos temporários:

"Que a imprensa seja o guia, a informadora e o veículo onde a multidão é transportada para outras regiôes - regiões progressistas; não há discutir, mas há a boa e a má imprensa, a imprensa

44 A VOZ DO TRABALHADOR, Porto Alegre, 11 de agosto de 1912, p. 3.

45 A LUTA, Porto Alegre, 14 de outubro de 1918, p. 1. 
que se dedica a deturpar a verdade, a bajular os mandões, seja Pedro ou Paulo, desde que lhes corra para o cofre o vil metal, e a imprensa que traçando-se um programa libertário, sacrifica-se para, após um número poder publicar outro sem ter que recorrer aos cofres dos potentados. A esta imprensa pertencemos nós. Duro é o nosso trabalho; dezenas de vezes no intervalo de um número a outro, o desânimo de nós se apodera e, se não fosse o grande amor que temos pela causa que abraçamos, já a esta hora o 'Syndicalista' teria deixado de existir". ${ }^{46}$

Esta "boa imprensa" a que se refere O Syndicalista tem o mais estrito sentido classista e daí sua importância. Tanto para o historiador, que identifica nela a linguagem e o discurso da emergência do trabalhador assalariado na cena política do Rio Grande do Sul e portanto, pode ver neste fenômeno uma transformação histórica ${ }^{47}$, quanto para o seu público destinatário, que tinha nela, sem intermediação classista, sua voz de combate como escreveu um colunista operário:

"É o dente da crítica, o dente que fere sem fazer sangue, mas que dói como costumam doer os dentes verdadeiros." 48

Entre 1892 e 1923 foram listados 91 títulos de jornais operários editados no Rio Grande do Sul ${ }^{49}$. Certamente esta relação não é definitiva. Neste período, apenas no ano de 1898 não foi registrada a fundação de nenhum órgão defensor dos trabalhadores. Embora muitos deles tivessem vida curta e irregularidade na circulação, quando vistos no seu conjunto ganham outra dimensão e importância. Expressam assim a presença e articulação de novos interesses classistas no estado. São os trabalhadores urbanos e assalariados de diversos setores do sistema produtivo, tanto imigrantes quanto também indivíduos aqui nascidos ou culturalmente formados, que vão tomando consciência política da organização social em que vivem e identificam interesses próprios que devem ser articulados e defendidos. Muito embora não passassem às vezes de pequenos grupos, são, porém, geralmente minorias atuantes e muitos deles militantes de "tempo integral", isto

O SYNDICALISTA, Porto Alegre, $2^{\text {a }}$ quinzena de março de 1921, p. 4.

47 THOMPSON, ob.cit., p. 57.

48 ECHO OPERÁRIO, Rio Grande, 28 de setembro de 1897, p. 2.

49 Ver JARDIM, Jorge Luiz Pastorisa. Comunicação e militância - A imprensa operária do Rio Grande do Sul (1892-1923). Porto Alegre: PUCRS, 1990 (dissertação de mestrado).
} 
é, totalmente dedicados à causa. Para difundir suas idéias e esta consciência aos demais trabalhadores, necessitam de um sistema de comunicação que as veicule por todo o estado, fazendo a propaganda das formas de luta já empregadas em outros centros e que aqui querem desenvolver.

O jornal, ao lado do sindicato e de outras formas de organização como o teatro, as escolas, as comemorações do $1^{\circ}$ de Maio etc., desempenhou um papel fundamental na circulação de idéias, na transplantação de métodos de luta e na formação política de seus leitores. Não era para menos todo o esforço que os militantes e líderes do movimento operário desenvolveram no sentido de criar, difundir e manter esta imprensa, verdadeira rede de comunicação alternativa aos veículos de informação dominantes em sua época. 